\title{
Gynaecological morbidity among HIV positive pregnant women in Cameroon
}

\author{
Enow R Mbu1, Eugene J Kongnyuy*2, FX Mbopi-Keou³, Rebecca N Tonye ${ }^{4}$, \\ Philip N Nana ${ }^{1}$ and Robert JI Leke ${ }^{1}$
}

Address: ${ }^{1}$ Department of Obstetrics and Gynaecology, Faculty of Medicine and Biomedical Sciences, University of Yaounde I, Cameroon, ${ }^{2}$ Child and Reproductive Health Group, Liverpool School of Tropical Medicine, UK, ${ }^{3}$ Department of Microbiology and Infectious Diseases, Faculty of Medicine and Biomedical Sciences, University of Yaounde I, Yaounde, Cameroon and ${ }^{4}$ Yaounde Central Hospital Maternity, Yaounde Central Hospital, Cameroon

Email: Enow R Mbu - rembu20012000@yahoo.com; Eugene J Kongnyuy* - kongnyuy@gmail.com; FX Mbopi-Keou - fomulunelson@yahoo.fr; Rebecca N Tonye - rtonye@yahoo.com; Philip N Nana - njotang@yahoo.com; Robert JI Leke - rebortjil@yahoo.com

* Corresponding author

Published: 3 July 2008

Reproductive Health 2008, 5:3 doi:10.1 186/1742-4755-5-3
Received: 22 June 2007

Accepted: 3 July 2008

This article is available from: http://www.reproductive-health-journal.com/content/5/1/3

(c) 2008 Mbu et al; licensee BioMed Central Ltd.

This is an Open Access article distributed under the terms of the Creative Commons Attribution License (http://creativecommons.org/licenses/by/2.0), which permits unrestricted use, distribution, and reproduction in any medium, provided the original work is properly cited.

\begin{abstract}
Objective: To compare the prevalence of gynaecological conditions among HIV infected and noninfected pregnant women.

Methods: Two thousand and eight (2008) pregnant women were screened for HIV, lower genital tract infections and lower genital tract neoplasia at booking antenatal visit.

Results: About 10\% (198/2008) were HIV positive. All lower genital tract infections except candidiasis were more prevalent among HIV positive compared to HIV negative women: vaginal candidiasis (36.9\% vs $35.4 \% ; p=0.678)$, Trichomoniasis $(21.2 \%$ vs $10.6 \% ; p<0.001)$, gonorrhoea ( $10.1 \%$ vs $2.5 \%$; $p<0.00 I)$, bacterial vaginosis $(2 I .2 \%$ vs $15.2 \%$; $p=0.026)$, syphilis ( $35.9 \%$ vs $10.6 \%$; $p<0.00 \mathrm{I}$ ), and Chlamydia trachomatis (38.4\% vs $7.1 \%$; $p<0.00 \mathrm{I}$ ). Similarly, HIV positive women more likely to have preinvasive cervical lesions: low-grade squamous intraepithelial lesion (SIL) $(18.2 \%$ vs $4.4 \% ; p<0.00 I)$ and high-grade squamous intraepithelial lesion $(I 2.1 \%$ vs $1.5 \%$; $p<$ $0.001)$.
\end{abstract}

Conclusion: We conclude that (i) sexually transmitted infections (STIs) are common in both HIV positive and HIV negative pregnant women in Cameroon, and (ii) STIs and preinvasive cervical lesions are more prevalent in HIV-infected pregnant women compared to their non-infected compatriots. We recommend routine screening and treatment of STIs during antenatal care in Cameroon and other countries with similar social profiles.

\section{Introduction}

There are three categories of reproductive morbidity obstetric, gynaecological and contraceptive morbidity. Gynaecological morbidity has been defined as 'any condition, disease or dysfunction of the reproductive system that is not related to pregnancy, abortion or childbirth but may be related to sexual behaviour' [1].

Gynaecological conditions are frequent in women infected with Human Immunodeficiency Virus (HIV). 
Both pregnancy and HIV/AIDS predispose women to certain gynaecological conditions because of modification of the immune system [2,3]. The Centers for Disease Control and Prevention (CDC) classification system for HIV infection includes several gynaecological conditions such as persistent, frequent or poorly responsive episodes of vaginal candidiasis, moderate or severe cervical intraepithelial neoplasia (CIN) and pelvic inflammatory disease (PID), chronic herpes simplex virus ulcers and invasive cervical cancer [4].

Korn and colleagues reviewed gynaecological disease in women infected with HIV and identified five categories: (i) lower genital tract neoplasia, (ii) pelvic inflammatory disease, (iii) menstrual disorders, (iv) sexually transmitted infections, (v) vaginitis and (vi) adverse effects of contraception [5].

Three of these categories are relevant in pregnancy, namely lower genital tract neoplasia, sexually transmitted infections and vaginitis. Pelvic inflammatory disease and menstrual disorders are not conditions we encounter in pregnancy.

Cameroon is one of the sub-Saharan African countries with a high prevalence of HIV $(6.8 \%$ among women of reproductive age) [6]. Only HIV and syphilis are screened routinely during antenatal care in Cameroon, despite the fact that HIV is known to be associated with other sexually transmitted infections [7]. After two decades of research on HIV, the prevalence of gynaecological conditions among HIV positive pregnant women is still unknown in Cameroon.

Gynaecological morbidity in HIV infected pregnant women has been largely ignored by research despite the frequency and severity of these conditions [8]. Previous research has focused mainly on gynaecological diseases in HIV positive non-pregnant women [9].

The aim of this study was to describe the frequency of gynaecological conditions among pregnant women and to compare the prevalence of these conditions among HIV positive and HIV negative pregnant women.

\section{Methods}

The study was conducted in a referral hospital (Yaounde Central Hospital) in Cameroon between January 2006 and December 2006. The study was approved by the Ethics Committee of the Faculty of Medicine and Biomedical Sciences (University of Yaounde I).

All data were collected during the booking antenatal visit. Pregnant women who received antenatal care during the period of study and gave consent to participate in the study were eligible for inclusion.

A detailed gynaecological and obstetrical history was taken followed by a clinical examination during the booking visit and any clinically detectable lesions were recorded. Laboratory investigations were carried out for gynaecological diseases known to be associated with HIV: cervical intraepithelial lesions (CIN), sexually transmitted infections and vaginitis. Only syphilis and HIV are screened routinely during antenatal care in Cameroon.

Determine rapid test (Abbott Laboratories, IL, USA) was used to screen for HIV. All reactive and doubtful samples were confirmed with the Western Blot test. Vaginal swabs were taken and a wet mount prepared in normal saline immediately after collection and examined for the presence of clue cells, yeast cells and motile Trichomonal vaginalis. Direct microscopic examination was performed on Gram-stained genital swabs for the detection of leukocytes and Gram-negative diplococci. Neisseria gonorrhea was isolated by inoculation of the genital swab on modified Thayer Martin media followed by incubation in a candle extinction jar at $36^{\circ} \mathrm{C}$ for $24-48$ hour. Identification of isolates was performed on the basis of colony morphology, visualization of Gram-negative diplococci, positive oxidase reaction and sugar fermentation tests. Bacterial vaginosis was diagnosed according to Amsel criteria [10]. Candidiasis was diagnosed by isolation of the Gram-positive yeast-like cells on Saboraud's dextrose agar and confirmed by a positive germ tube test. Syphilis was diagnosed if both Venereal Disease Research Laboratory (VDRL) and Treponema Pallidum Hemagglutination Assay (TPHA) were positive. A positive VDRL and negative TPHA was considered false positive. A positive TPHA test alone was interpreted as evidence of a past infection. Chlamydia trachomatis was diagnosed by Micro Trak (Syva Co., Palo Alto, Calif.) direct immunofluorescence test of cervical scrapings [11].

Data was entered into SPSS Version 13. Descriptive statistics such as proportions were analysed and presented. Univariate analyses, using odds ratio (OR) and Chisquare test for association were conducted to assess the association between HIV status and gynaecological conditions. All significance tests were two-tailed and statistical significance was defined at the $5 \%$ alpha level.

\section{Results}

Two thousand and eight (2008) women participated in the study. Six hundred and thirty eight women $(31.8 \%)$ had their booking visit during the first trimester, 1210 women $(60.3 \%)$ during the second trimester and 160 women $(8.0 \%)$ women during the third trimester. 


\section{Socio-demographic characteristics of study population}

Socio-demographic characteristics of the study participants are shown in Table 1 . The mean age was 28 years (standard deviation $[S D]=9.1$ ). A majority $(58.0 \%)$ of the women were aged 20-29 years. About 20.0\% were nulliparous women, while $38.0 \%$ had four previous deliveries or more. Most of them were married (58.0\%) and had secondary education or higher (58.2\%). Up to $90.0 \%$ of the study population came from urban area and the rest were from rural areas closed to the capital city (Yaounde).

\section{Prevalence of HIV}

Of the 2008 women tested for HIV, 198 were HIV positive, giving an overall HIV prevalence of 9.9\% among pregnant women during their booking ANC visit.

\section{Prevalence of gynaecological morbidity}

The prevalence of gynaecological conditions among pregnant women by HIV status is presented in Table 2. All genital tract infections except candidiasis were more prevalent among HIV positive compared to HIV negative women: vaginal candidiasis $(36.9 \%$ vs $35.4 \%)$, Trichomoniasis (21.2\% vs $10.6 \%)$, gonorrhoea ( $10.1 \%$ vs $2.5 \%)$, bacterial vaginosis (21.2\% vs $15.2 \%)$ and Chlamydia trachomatis (38.4\% vs $7.1 \%)$. The prevalence of syphilis was also higher among HIV positive women (35.9\% vs $10.6 \%$ ). Similarly, HIV positive women had a higher prevalence of preinvasive cervical lesions: low-grade squamous intraepithelial lesion (SIL) (18.2\% vs 4.4\%) and high-grade squamous intraepithelial lesion (12.1\% vs $1.5 \%)$.

Table I: Socio-demographic characteristics of study population.

\section{Discussion}

This study compared the prevalence of gynaecological morbidity among pregnant women, according to their HIV serostatus identified during antenatal care. Sexually transmitted infections (STIs) and preinvasive cervical lesions were found to be more prevalent among HIV infected pregnant women compared to their non-infected counterparts.

The high prevalence of STIs among HIV positive women has previously been reported [5]. Sexually transmitted infections producing ulcerative lesions such as syphilis, chancroid and genital herpes simplex virus (HSV) are associated with a higher rate of HIV transmission [5]. Non-ulcerative STIs are also associated with a three- to five-fold increase in the risk of HIV acquisition [7]. Chaisilwattana et al (1997) reported a higher prevalence of gonorrhoea and Chlamydia trachomatis among HIV pregnant women [12]. Gonorrhoea increases the risk for pelvic inflammatory disease, infertility, ectopic pregnancy, and acquisition and transmission of human immunodeficiency virus (HIV) [13]. HIV infection and STIs have common risk factors, and STIs increase the risk of acquisition of HIV. Some studies failed to find an association between HIV and STIs, and this has been explained by insufficient statistical power to detect the association [14].

It is not clear whether HIV infection increases the risk of acquisition of vaginal infections, but these conditions are common among sexually active women. Candida albucans and other Candida species are known to cause symptomatic infections in women with certain risk factors such as diabetes mellitus, broad spectrum antibiotics and immu-

\begin{tabular}{|c|c|c|c|}
\hline Characteristic & $\begin{array}{c}\text { HIV Positive } \\
(\%) \\
(\mathbf{N}=\mid 98)\end{array}$ & $\begin{array}{c}\text { HIV negative } \\
(\%) \\
(\mathrm{N}=|8| 0)\end{array}$ & $\begin{array}{c}\begin{array}{c}\text { Total } \\
(\%)\end{array} \\
(\mathrm{N}=2008)\end{array}$ \\
\hline \multicolumn{4}{|l|}{ Age } \\
\hline$<20$ years & $25 / 198(12.6)$ & $380 / 1810(21.0)$ & $405 / 2008(20.2)$ \\
\hline $20-29$ years & $120 / 198(60.6)$ & $1044 / 1810(57.7)$ & I I 64/2008 (58.0) \\
\hline$\geq 30$ years & $53 / 198(26.8)$ & $386 / 1810(21.3)$ & $439 / 2008(21.9)$ \\
\hline \multicolumn{4}{|l|}{ Parity } \\
\hline 0 & $30 / 198(15.2)$ & $375 / 1810(20.7)$ & $407 / 2008(20.3)$ \\
\hline $1-3$ & $78 / 198(39.4)$ & $766 / 1810(42.3)$ & $844 / 2008(42.0)$ \\
\hline$\geq 4$ & $90 / 198(45.5)$ & $667 / 1810(36.9)$ & $757 / 2008$ (37.7) \\
\hline \multicolumn{4}{|l|}{ Marital status } \\
\hline Single & $75 / 198$ (37.9) & $769 / 1810(42.5)$ & $844 / 2008(42.0)$ \\
\hline Married & $123 / 198(62.1)$ & $10571810(58.4)$ & I I 64/2008 (58.0) \\
\hline \multicolumn{4}{|l|}{ Education } \\
\hline No formal education & $29 / 198(14.6)$ & $168 / 1810(9.3)$ & 197/2008 (9.8) \\
\hline Primary & $69 / 198(34.8)$ & $573 / 1810(31.7)$ & $642 / 2008(32.0)$ \\
\hline Secondary or higher & $100 / 198(50.5)$ & $1069 / 1810(59.1)$ & $1169 / 2008$ (58.2) \\
\hline \multicolumn{4}{|l|}{ Residence } \\
\hline Rural & $8 / 198(4.0)$ & $189 / 1810(10.4)$ & $196 / 2008(9.8)$ \\
\hline Urban & $190 / 198(96.0)$ & $1622 / 1810(89.6)$ & $1812 / 2008(90.2)$ \\
\hline
\end{tabular}


Table 2: Gynaecological conditions among pregnant women at booking visit by HIV status.

\begin{tabular}{|c|c|c|c|c|}
\hline Gynaecological condition & $\begin{array}{c}\text { HIV positive } \\
(\%) \\
(\mathrm{N}=198)\end{array}$ & $\begin{array}{c}\text { HIV negative } \\
(\%) \\
(\mathrm{N}=1810)\end{array}$ & $\begin{array}{c}\text { Prevalence rate } \\
\text { ratio } \\
(95 \% \mathrm{Cl})\end{array}$ & p-value \\
\hline Candidiasis & $73(36.9)$ & $640(35.4)$ & $1.04(0.86-1.26)$ & 0.678 \\
\hline Trichomoniasis & $42(21.2)$ & $192(10.6)$ & $2.00(1.48-2.70)$ & $<0.001$ \\
\hline Gonorrhoea & $20(10.1)$ & $46(2.5)$ & $3.98(2.40-6.58)$ & $<0.001$ \\
\hline Bacterial vaginosis & $42(21.2)$ & $274(15.2)$ & $1.40(1.05-1.87)$ & 0.026 \\
\hline Syphilis & 71 (35.9) & $192(10.6)$ & $3.37(2.69-4.23)$ & $<0.001$ \\
\hline Chlamydia infection & $76(38.4)$ & $128(7.1)$ & $5.43(4.26-6.92)$ & $<0.001$ \\
\hline Low-grade SIL & $36(18.2)$ & $80(4.4)$ & $4.11(2.86-5.93)$ & $<0.001$ \\
\hline High-grade SIL & $24(12.1)$ & $27(1.5)$ & $8.13(4.78-13.80)$ & $<0.001$ \\
\hline
\end{tabular}

SIL = squamous intraepithelial lesion

nosuppression therapy [5]. Vaginal candidiasis is also frequent in pregnancy. Leroy et al (1995) reported a similar prevalence of vaginal candidiasis among HIV-infected pregnant women $(22.3 \%)$ and non-infected pregnant women $(20.1 \%)$ [15]. The prevalence of vaginal candidiasis in HIV-infected women depends on the CD4 count. Burns et al (1997) reported a 3-fold increase in vaginal candidiasis among HIV-infected women with low CD4 counts compared to HIV-infected women with normal CD4 count during pregnancy [16]. Apart from Candida spp, we reported an increase in the prevalence of bacterial vaginosis (BV) among HIV pregnant women. Bacterial vaginosis increases susceptibility to infection by HIV and other genital tract pathogens, but it is not clear whether HIV increases the risk of developing BV [17].

We reported an 8-fold increase in high grade SIL among HIV infected pregnant women compared to their noninfected compatriots. A 5-fold increase in cervical intraepithelial neoplasia among HIV-infected women has been described previously [5]. There is evidence that the severity of preinvasive cervical lesion is related to the degree of immunosuppression, suggesting that immunosupprsession contributes (at least in part) to the risk of developing preinvasive lesion $[18,19]$. Some studies suggest that the high prevalence of preinvasive cervical lesion may be related to concurrent risk factors related to the mode of transmission of HIV [20]. Ahr et al (2006) reported that HIV positive women with low CD4 count had a higher prevalence of human papilloma virus (HPV) and preinvasive cervical lesion was more frequent in women with HPV [21]. HPV is a known causative agent for preinvasive and invasive lesions of the cervix.

This study has some limitations. First of all, we relied on clinically detectable lesions for the diagnosis of genital herpes simplex virus and chancroid. Secondly, high levels of cardiolipin antibodies associated with HIV infection could interfere with serologic tests for syphilis and give false positive results [5].
We conclude that (i) STIs are common in both HIV positive and HIV negative women in Cameroon, and (ii) STIs and preinvasive cervical lesions are more prevalent in HIV-infected pregnant women compared to their noninfected compatriots. We recommend routine screening and treatment of STIs during antenatal care in Cameroon and countries with similar social profiles.

\section{Competing interests}

The authors declare that they have no competing interests.

\section{Authors' contributions}

ERM, EJK conception, design, drafting of the protocol, analysis and interpretation. Both authors contributed equally to the realisation of this paper, FXMK, RNT, PNN, RJLL critically revising the final article for important intellectual content. All authors read and approved the manuscript.

\section{Acknowledgements}

We wish to acknowledge the Faculty of Medicine of the University of

Yaounde for providing resources for this study.

\section{References}

I. Broek N van den: Gynaecological Morbidity. Tropical Doctor 2007, 37:65.

2. Temmerman M, Chomba EN, Ndinya-Achola J, Plummer FA, Coppens $M$, Piot $P$ : Maternal Human Imminodefiency virus - infection and pregnancy outcome. Obstet Gynecol 1994, 83:495-50I.

3. Handkins CA, Handley MA: HIV disease and AIDS in women: Current Knowledge and a research agenda. J Acquir Immune Defic Syndr 1992, 5(10):957-71.

4. CDC: Revised classification for HIV infection and expanded surveillance case definition of AIDS among adolescents and adults. MMWR 1993, 41: I I-19.

5. Korn AP, Landers DV: Gynecologic disease in women infected with human immunodeficiency virus type I. J Acquir Immune Defic Syndr Hum Retrovirol 1995, 9:36I-70.

6. Cameroon National Institute of Statistics, ORC Macro: Cameroon Demographic and Health Survey 2004. Calverton, Maryland USA: NIS and ORC Macro; 2004.

7. Kongnyuy EJ, Tenang MS, Chiabi A, Fomulu N, Doh AS: HIV discordant couples: what is new? Clinics in Mother and Child Health 2005, 2(I):275-28I.

8. Cejtin HE: Gynecologic issues in the HIV-infected woman. Obstet Gynecol Clin North Am 2003, 30:71 I-729. 
9. Aaron $E$, Levine $A B$ : Gynecologic care and family planning for HIV-infected women. AIDS Read 2005, 15:420-428.

10. Amsel R, Totten PA, Spiegel CA, Chen KC, Eschenbach D, Holmes KK: Non-specific vaginitis: diagnostic criteria and microbial and epidemiological associations. Am J Med I983, 74: I4-22.

II. Williams T, Maniar AC, Brunham RC, Hammond GW: Identification of Chlamydia trachomatis by direct immunofluosrescence applied to specimens originating from remote areas. Journal of Clinical Microbiology 1985, 22: I053-1054.

12. Chaisilwattana P, Chuachoowong R, Siriwasin W, Bhadrakom C, Mangclaviraj Y, Young NL, Chearskul S, Chotpitayasunondh T, Mastro TD, Shaffer N: Chlamydial and gonococcal cervicitis in HIVseropositive and HIV-seronegative pregnant women in Bangkok: prevalence, risk factors, and relation to perinatal HIV transmission. Sex Transm Dis 1997, 24(9):495-502.

13. Centers for Disease Control and Prevention (CDC): Increases in gonorrhea - eight western states, 2000-2005. MMWR Morb Mortal Wkly Rep 2007, 56( I 0):222-225.

14. Joffe H, Bamberger E, Nurkin S, Kedem E, Kra-Oz Z, Pollack S, Srugo I: Sexually transmitted diseases among patients with human immunodeficiency virus in northern Israel. Isr Med Assoc J 2006, 8:333-336.

15. Leroy V, De Clercq A, Ladner J, Bogaerts J, Perre P Van de, Dabis F: Should screening of genital infections be part of antenatal care in areas of high HIV prevalence? A prospective cohort study from Kigali, Rwanda, 1992-1993. The Pregnancy and HIV (EGE) Group. Genitourin Med 1995, 71:207-I I.

16. Burns DN, Tuomala R, Chang BH, Hershow R, Minkoff H, Rodriguez E, Zorrilla C, Hammill H, Regan J: Vaginal colonization or infection with Candida albicans in human immunodeficiency virus-infected women during pregnancy and during the postpartum period. Women and Infants Transmission Study Group. Clin Infect Dis 1997, 24:20I-210.

17. St John E, Mares D, Spear GT: Bacterial vaginosis and host immunity. Curr HIVIAIDS Rep 2007, 4:22-28.

18. Nicol AF, Nuovo G], Salomão-Estevez A, Grinsztein B, Tristão A, Russomano F, Lapa E, Silva JR, Oliveira MP, Pirmez C: Immune factors involved in the cervical immune response in the HIVI HPV co-infection. J Clin Pathol 2008, 6 I ( I):84-8.

19. Zarcone R, Bellini P, Carfora E, Longo M, Monarca M, Tomasillo G, Lizza R: Incidence of CIN in HIV-positive women. Minerva Ginecol 1998, 50:181-3.

20. Parham GP, Sahasrabuddhe VV, Mwanahamuntu MH, Shepherd BE, Hicks ML, Stringer EM, Vermund SH: Prevalence and predictors of squamous intraepithelial lesions of the cervix in HIVinfected women in Lusaka, Zambia. Gynecol Oncol 2006, 103:1017-1022.

21. Ahr A, Rody A, Cimposiau C, Faul-Burbes C, Kissler S, Kaufmann M, Gätje R: Cervical cancer screening of HIV-positive women: is a prolongation of the screening interval meaningful? Zentralbl Gynakol 2006, I 28:242-245. 